\title{
Comparison of different skeletal muscles from growing domestic pigs and wild boars
}

\author{
Dorothea Lösel*, Anja Franke* and Claudia Kalbe \\ Leibniz Institute for Farm Animal Biology, Institute of Muscle Biology and Growth, Dummerstorf, Germany
}

\begin{abstract}
The domestication process of pigs was associated with substantial morphological and physiological changes. The aim of this study was to comparatively investigate muscle microstructure and biochemical properties of four different skeletal muscles (M. longissimus, M. semitendinosus, M. psoas major, M. rhomboideus) in growing domestic pigs $(\mathrm{n}=5)$ and wild boars $(n=4)$. The superiority of domestic pigs in body and muscle growth at three months of age was reflected by a 4-fold body weight and higher absolute weights of heart, liver and muscles. Relative muscle weights of $M$. psoas major and M. rhomboideus were reduced, whereas a 1.6-fold heavier $M$. semitendinosus was observed in domestic pigs compared with wild boars. In addition, the muscle cross-sectional area was greater in all muscles of domestic pigs resulting from about 3-fold fibre cross-sectional area, whereas total fibre number remained unchanged. As a consequence of intensified fibre hypertrophy, the fibre area per capillary is higher in all muscles of domestic pigs. Thus, the impaired supply with oxygen and nutrients may be one reason for the shift to the glycolytic muscle metabolism as indicated by a greater proportion of fast-twitch glycolytic fibres at the expense of fast-twitch oxidative fibres. This is also reflected by a higher ratio of lactate dehydrogenase to isocitrate dehydrogenase activity. Our data suggest that the intensified muscle growth was realized by myofibre hypertrophy at unchanged myofibre number in growing domestic pigs. It seems that domestication-induced changes were most pronounced in $M$. semitendinosus as the exterior ham muscle which may be related to muscle specific selection for lean growth.
\end{abstract}

Keywords: wild boar, domestic pig, skeletal muscle properties, domestication, myofibre type

Archiv Tierzucht 56 (2013) 76, 766-777

doi: $10.7482 / 0003-9438-56-076$

Corresponding author:

Claudia Kalbe; email: kalbe@fbn-dummerstorf.de

Institute of Muscle Biology and Growth, Leibniz Institute for Farm Animal Biology, Wilhelm-Stahl-Allee 2, 18196

Dummerstorf, Germany

() 2013 by the authors; licensee Leibniz Institute for Farm Animal Biology (FBN), Dummerstorf, Germany. This is an Open Access article distributed under the terms and conditions of the Creative Commons Attribution 3.0 License (http://creativecommons.org/licenses/by/3.0/).
Received: 25 March 2013

Online: 17 June 2013
Accepted: 10 June 2013

*Both authors contributed equally to this paper. 
Abbreviations: CK: creatine kinase, DP: domestic pig, FCSA: fibre cross-sectional area, FTG: fast-twitch glycolytic, FTO: fast-twitch oxidative, ICDH: isocitrate dehydrogenase, MCSA: muscle cross-sectional area, LD: M. longissimus, LDH: lactate dehydrogenase, PM: M. psoas major, RH: M. rhomboideus, ST: M. semitendinosus, STO: slow-twitch oxidative, WB: wild boar

\section{Introduction}

Domestication of livestock began about 8000 to 10000 years before present and was driven by the demand for human food sources (reviewed in Mignon-Grasteau et al. 2005). The domestication of wild boars (WB; Sus scrofa L.) occurred about 9000 years ago (Giuffra et al. 2000) and took place in multiple and independent centres of domestication (Larson et al. 2005). This process was associated with substantial morphological, physiological and psychological changes in the domestic pigs (DP; Sus scrofa domestica) compared with the wild ancestors. For instance, WB have 19 vertebrae, whereas European DP have 21-23 (King \& Roberts 1960). The phenotypic differences between commercially-used pig breeds and their wild counterparts are generated by the strong selection processes and the limited housing conditions of DP. One main focus of selection was optimization of pigs for meat production and therefore, DP were adapted to lean growth with high protein and low fat content.

Skeletal muscle forms the basis of the product meat and thus this tissue is of special economic interest. There are some studies that have provided knowledge on morphological and physiological properties of muscle fibres in domestic and wild pigs (e.g. Weiler et al. 1995, Fiedler et al. 1998, Müller et al. 2002, Rehfeldt et al. 2008). This knowledge is important, because for instance myofibre type composition or fibre size are related to economically important traits like meat quality or lean accretion (Larzul et al. 1997, Bee 2004).

The aforementioned studies comparing skeletal muscles of DP and WB revealed strong evidence for increased fibre sizes, a predominance of fast-twitch (llb) myofibres and a general switch to more glycolytic metabolism in the modern pig breeds (Essén-Gustavsson \& Lindholm 1984, Weiler et al. 1995, Rehfeldt et al. 2008).

The aim of the present study was to evaluate the effects of domestication on skeletal muscle tissue of growing DP and WB. Therefore, as an initial step we pointed out the phenotypic differences in terms of live weight, crown-rump length and weights of selected organs and skeletal muscles of three months-old DP and WB. The main aim, however, was to investigate the effects of domestication on muscle microstructure and biochemical properties of four different skeletal muscles (m. longissimus [LD], m. semitendinosus [ST], m. rhomboideus [RH] and m. psoas major [PM]).

\section{Material and methods}

\section{Animals}

All procedures were in accordance with the German Law of Animal Protection. For this study we used five subadult DP (German Landrace; one male, four females) and four European WB (one male, three females). All animals were about three months old (DP $95 \pm 3 \mathrm{~d}$; WB $92 \pm 3 \mathrm{~d} ; P=0.475$ ). The DP were kept in group housing in the experimental pig unit of the Leibniz Institute for Farm Animal Biology (FBN, Dummerstorf, Germany) and were fed ad 
libitum with typical commercial diets (Trede \& von Pein, Dammfleth, Germany) according to recommendations for growing pigs (GFE 2006). The WB were obtained from the zoological garden Schwerin (Germany) where they lived within their family groups and had free access to feed and sows' milk. All WB were littermates, whereas among the DP two animals were littermates and three originated from different sows mated with the same boar. All pigs were killed at the slaughterhouse of the FBN after electrostunning (DP) or anaesthesia (WB) with an intramuscular injection of ketamine hydrochloride (Ursotamin $10 \%$, Serumwerk Bernburg AG, Bernburg, Germany) and azaperone (Stresnil, Janssen-Cilag GmbH, Neuss, Germany). Body weight, crown-rump length and the weights of heart and liver were recorded. The right ST, RH, PM were removed as a whole, weighed and the circumference at the muscle mid-belly was recorded. Samples from LD at the level of the 13th/14th rib, from the mid-belly of RH and PM and from the dark (deep), bright (superficial) and central portion of ST were taken for histological and biochemical analyses. Samples were collected within 10 min post mortem, snap-frozen in liquid nitrogen and stored at $-80^{\circ} \mathrm{C}$.

\section{Histochemistry and microscopy}

Muscle cross-sectional area (MCSA) was calculated from the circumference of the muscle mid-belly. Serial transverse sections of $10 \mu \mathrm{m}$ were cut at $-20^{\circ} \mathrm{C}$ in a cryostat (Leica, Nussloch, Germany). One section was stained for cytoplasm with eosin and for alkaline phosphatase to visualize capillaries. Another section was exposed to the combined reaction for NADHtetrazolium reductase (Novikoff et al. 1961) and acid pre-incubated ATPase at pH 4.2 (Guth \& Samaha 1970) which enables classification into slow-twitch oxidative (STO), fast-twitch oxidative (FTO) and fast-twitch glycolytic (FTG) fibres. Fibre type distribution, fibre crosssectional area (FCSA) and capillary distribution were determined on 900 muscle fibres in the ST (300 each in the dark, central and bright region) and on 300 muscle fibres each in LD, PM and RH by image analysis (AMBA, IBSB, Berlin, Germany). The estimated total fibre number was obtained by multiplying the fibre number per unit area by the MCSA. In LD, the estimation of total fibre number would be inaccurate because muscle fibres do not run parallel to the longitudinal muscle axis. Therefore, no value for LD total fibre number is given.

\section{Biochemical analyses}

A sample of $100 \mathrm{mg}$ muscle tissue was homogenized on ice in $2 \mathrm{ml}$ potassium phosphate buffer ( $\mathrm{pH}=6.9$ ) using a Potter Elvehjem Tissue Grinder (Wheaton, Milleville, NJ, USA) and analyzed for DNA, RNA and protein concentrations and the activities of creatine kinase (CK), lactate dehydrogenase (LDH) and isocitrate dehydrogenase (ICDH). Deoxyribonucleic acid was measured fluorometrically against a standard of calf thymus DNA (Sigma-Aldrich Chemie GmbH, Steinheim, Germany) after using Hoechst 33258 (Sigma-Aldrich) according to Rehfeldt \& Walther (1997). Ribonucleic acid was quantified fluorometrically with SYBR Green II (Molecular Probes, Eugene, OR, USA) against RNA from calf liver (Sigma-Aldrich) as a standard according to Oksbjerg et al. (2000). In both assays, fluorescence was measured using an Flx-800-I microplate reader (Bio-Tek Instruments Inc., Bad Reichenhall, Germany). Protein concentration was determined according to Peterson (1977) against a bovine serum albumin (Serva, Heidelberg, Germany) standard and CK activity was measured in supernatants of 
diluted (1:10) muscle homogenates at $37^{\circ} \mathrm{C}$ using a commercial kit (Biomed, Oberschleissheim, Germany). The activities of $\mathrm{LDH}$ and ICDH were measured using modified assay protocols according to SIGMA (http://www.sigmaaldrich.com/life-science/metabolomics/enzymeexplorer/learning-center/assay-library.html). All assays were adapted to microplates and the optical density was measured using a Spectramax Plus384 plate reader (Molecular Devices Corporation, Sunnyvale, CA, USA).

\section{Statistical analysis}

For statistical analyses, data were subjected to one-factor ANOVA (factor genotype: domestic pig vs. wild boar) and least squares means ( $L S M \pm S E)$ were estimated and tested by $t$-Test (Proc MIXED, SAS v9.2, SAS Inst. Inc., Cary, NC, USA).

\section{Results and discussion}

Body, organ and muscle weights

At similar age DP exhibited a nearly 4 -fold body weight (DP $47.3 \pm 3.3 \mathrm{~kg}$; WB $12.7 \pm 3.7 \mathrm{~kg}$; $P<0.001$ ) and a 1.5-fold crown-rump length (DP 88.6 $\pm 2.4 \mathrm{~cm} ; \mathrm{WB} 58.0 \pm 2.7 \mathrm{~cm} ; P<0.001)$. This observation is in agreement with the study of Rehfeldt et al. (2008), who also showed 4-fold higher body weights in 20 weeks-old DP compared with their wild counterparts. In addition, several studies demonstrated the predominant live weight of DP at different ages (e.g. Bader 1983, Weiler et al. 1998). Consequently, the absolute weights of liver (4-fold; $P<0.001)$, heart (2.7-fold; $P<0.001)$, PM (3.5-fold; $P<0.001)$, RH (2.5-fold; $P=0.002)$ and ST (5.8-fold; $P<0.001)$ were greater in DP than in WB (Table 1).

Table 1

Absolute and relative weights of muscles and organs in wild boar and domestic pig (LSM $\pm S E$ )

\begin{tabular}{lccc}
\hline & Wild boar & Domestic pig & $P$ \\
\hline M. semitendinosus, g & $35.8 \pm 14.5$ & $209 \pm 13$ & $<0.001$ \\
M. semitendinosus, $\%$ & $0.28 \pm 0.02$ & $0.44 \pm 0.01$ & $<0.001$ \\
M. psoas major, g & $55 \pm 18$ & $190 \pm 16$ & $<0.001$ \\
M. psoas major, \% & $0.43 \pm 0.01$ & $0.40 \pm 0.01$ & 0.054 \\
M. rhomboideus, g & $22.56 \pm 4.94$ & $55.86 \pm 4.42$ & 0.002 \\
M. rhomboideus, \% & $0.18 \pm 0.02$ & $0.12 \pm 0.02$ & 0.028 \\
Heart, g & $73.7 \pm 12.8$ & $198.4 \pm 11.4$ & $<0.001$ \\
Heart, \% & $0.58 \pm 0.02$ & $0.42 \pm 0.01$ & $<0.001$ \\
Liver, g & $285 \pm 82$ & $1136 \pm 74$ & $<0.001$ \\
Liver, \% & $2.24 \pm 0.08$ & $2.41 \pm 0.07$ & 0.166 \\
\hline
\end{tabular}

In accordance with our results, Müller et al. (2000) found greater absolute weights of liver and hearts in Pietrain pigs compared with WB. However, the relative organ and muscle weights (percentage of live body weight) gave an entirely different picture (Table 1). The relative heart weight was $27 \%$ lower in DP than in WB $(P<0.001)$, whereas the relative liver weight did not differ between genotypes $(P=0.166)$. Lower relative heart weights in DP but no differences in relative liver weights between WB and DP were also reported by Schurmann (1984). In addition, relative heart weights of WB $(0.64 \%)$ and DP $(0.29 \%)$ are reviewed in Wegner 
(1971). The author concluded that domestication results in a heart reduction in many species, which might be associated with the reduced physical activity. Our relative liver weights of WB are in agreement with Müller et al. (2000), but much higher than values reported by Wolkers et al. (1994). In contrast to Wolkers et al. (1994), in our study the relative liver weights did not differ between WB and DP. The value $2.41 \%$ relative liver weight for DP is quite high (vs. $1.32 \%$ in $210 \mathrm{~d}$-old Pietrain pigs reported by Müller et al. (2000)). One possible explanation could be that at the age of three months liver growth is in a good accordance with body growth, while at slaughter age the body growth is much more accelerated due to selection. This fits to our former study, in which the relative liver weight in $83 \mathrm{~d}$-old pigs comprised $2.28 \%$ (unpublished data) and in $188 \mathrm{~d}$-old Landrace pigs exhibited $1.60 \%$ (Rehfeldt et al. 2012). The relative $P M$ weight tended to be lower in $\mathrm{DP}(P=0.054)$ and the relative $\mathrm{RH}$ weight was $33 \%$ lower in DP than in WB $(P=0.028)$. In contrast, a 1.6 -fold relative muscle weight was observed for ST $(P<0.001)$. Rehfeldt et al. (2008) suggested that the PM muscle seems to be proportionally, whereas the ST muscle seems to be disproportionally enlarged in DP. This may be related to muscle specific selection for lean growth. Regardless of the economic relevance of both muscles, the exterior ham muscle (ST) exhibits more growth capacity than the interior tenderloin muscle (PM).

\section{Muscle structural properties}

No differences in the proportion of STO fibres could be detected between WB and DP in any of the muscles examined (Figure 1). All muscles showed a lower percentage of FTO fibres in DP. The greatest reduction in the percentage of FTO fibres was found in LD with a $54 \%$ lower proportion $(P<0.001)$, whereas in ST, PM and RH FTO proportion was reduced by $35 \%$ $(P<0.001), 30 \%(P=0.002)$ and $30 \%(P=0.094)$, respectively.

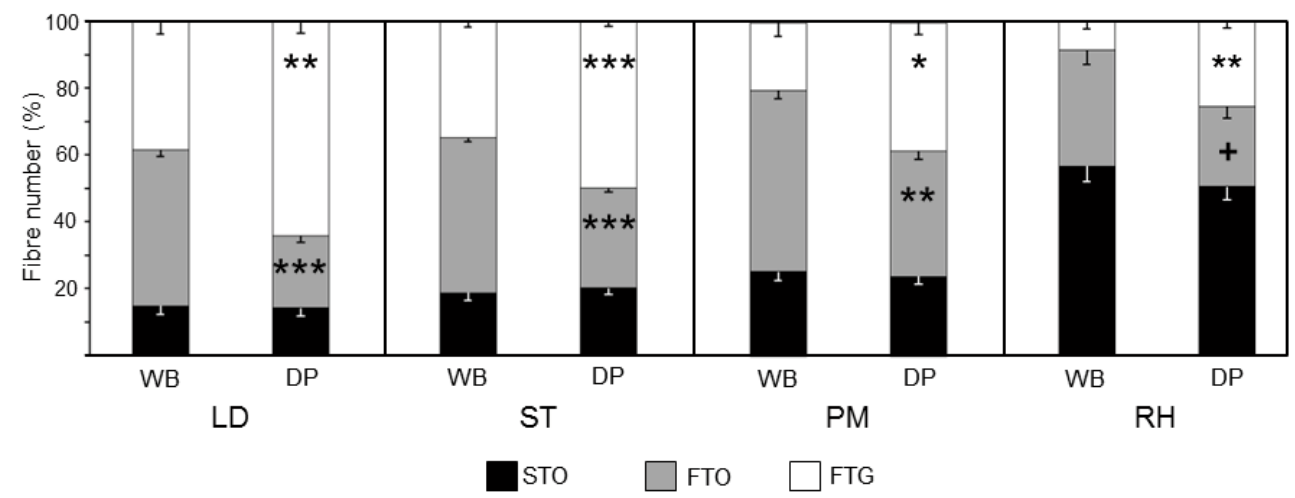

Figure 1

Proportions of fibre types in cross sections of LD, ST, PM and RH of WB and DP. LSM and SE are presented as columns and error bars, respectively. $+P=0.09 ;{ }^{*} P<0.05 ;{ }^{*} P<0.01 ;{ }^{* *} P<0.001$

The greatest relative changes occurred in the proportion of FTG fibres which was 1.7-fold higher in LD $(P=0.002)$, 1.4-fold in ST $(P<0.001)$, 1.9-fold in PM $(P=0.014)$ and 2.9-fold in RH $(P=0.001)$ of $D P$. Thus, the muscle which displayed the smallest proportion of FTG fibres in 
WB showed the greatest increase in this fibre type as a result of domestication. Consistent results were reported by Bader (1983) for LD and PM, by Essén-Gustavsson \& Lindholm (1984) for LD, ST and M. gluteus, by Rehfeldt et al. (2008) for LD, ST and PM, by Weiler et al. (1995) for M. gracilis and by Ruusunen \& Puolanne (2004) for LD, M. semimembranosus and M. gluteus superficialis.

The MCSA more than doubled in LD, RH and PM ( $P \leq 0.007$; Table 2), whereas it was 3.8fold in ST $(P<0.001)$. Muscle cross-sectional area is the result of both total fibre number and mean fibre size. However, no differences between WB and DP could be observed in total fibre number in any of the muscles examined. Total fibre numbers in WB and DP amounted $762 \pm 42$ vs. $847 \pm 38 \times 10^{3}(P=0.177)$ in ST, $943 \pm 57$ vs. $816 \pm 51 \times 10^{3}(P=0.142)$ in PM and $364 \pm 48$ vs. $257 \pm 41 \times 10^{3}(P=0.124)$ in $\mathrm{RH}$. This is in contrast to the results of Rehfeldt et al. (2008) where the total fibre number in DP was greater in ST and smaller in PM compared with WB at both 7 and 20 weeks of age. Therefore, the greater MCSA in DP in our study can only be accounted for muscle fibre hypertrophy. Domestic pigs exhibited greater FCSA in all fibre types and in all muscles examined $(P \leq 0.003)$. The extent of increase ranged from 2 - to 4 -fold and was similar both among fibre types and among muscles. Irrespective of fibre type, the average FCSA was 3-fold in LD $(P<0.001)$, 3.4-fold in ST ( $P<0.001)$, 2.9-fold in PM ( $P=0.002)$ and 3.2-fold in $\mathrm{RH}(P=0.002$; data not shown). A substantial increase in FCSA in DP compared with WB has also been reported by Bader (1983), Weiler et al. (1995) and Rehfeldt et al. (2008). In addition, the number of fibres per unit area, which is an inverse expression of FCSA, was only $30-36 \%$ in DP compared with WB in all muscles $(P<0.001)$. In LD, the number of capillaries associated with one fibre tended to be smaller in DP compared with WB $(P=0.087)$, but no differences between wild and domestic pigs could be detected in the other muscles. Similarly, the number of capillaries per myofibre only tended to be smaller in ST muscle of DP at 7 weeks of age, but was not different in LD or PM muscles or at 20 weeks of age (Rehfeldt et al. 2008). However, because of the highly hypertrophied fibres in DP, remarkable differences were found in the fibre area supplied by one capillary. In DP, the average fibre area supplied by one capillary was $415 \%$ in LD, $560 \%$ in ST, $230 \%$ in PM and $360 \%$ in RH compared with WB $(P \leq 0.032)$. These differences were significant or tended to be significant for all fibre types in all muscles. The greatest increase was found in ST which is in accordance with the greatest increase of FCSA. This is consistent with the study of Rehfeldt et al. (2008) who observed greater fibre areas per capillary in LD, ST and PM at 7 and 20 weeks of age. Similarly, the smaller number of capillaries per unit area reported by Ruusunen \& Puolanne (2004) for DP muscles is also the result of fibre hypertrophy.

\section{Biochemical properties of skeletal muscle}

It is not surprising that the total amounts of DNA, RNA and protein were remarkably greater in DP than in WB in ST, PM and RH (Table 3) due to the higher absolute muscle weights (weight of LD not determined). However, in each muscle, lower DNA concentrations were found in DP than in WB with $-16 \%$ in LD $(P=0.001),-20 \%$ in ST $(P<0.001),-25 \%$ in PM $(P=0.001)$ and $-17 \%$ in $\mathrm{RH}(P=0.025)$. This is in agreement with the finding of Rehfeldt et al. (2008) and most likely due to a lower density of nuclei per fibre area in DP muscles. On the one hand, this results from the smaller number of fibres per unit area in DP muscle. 
Table 2

Microstructural characteristics LD, ST, PM and RH in wild boar and domestic pig (LSM \pm SE)

\begin{tabular}{|c|c|c|c|}
\hline & Wild boar & Domestic pig & $P$ \\
\hline \multicolumn{4}{|c|}{$\mathrm{MCSA}, \mathrm{cm}^{2}$} \\
\hline LD & $11.4 \pm 2.9$ & $29.0 \pm 2.6$ & 0.003 \\
\hline ST & $5.8 \pm 1.4$ & $21.7 \pm 1.3$ & $<0.001$ \\
\hline PM & $5.0 \pm 0.9$ & $12.2 \pm 0.8$ & $<0.001$ \\
\hline $\mathrm{RH}$ & $2.3 \pm 0.5$ & $5.1 \pm 0.5$ & 0.007 \\
\hline \multicolumn{4}{|c|}{ FCSA STO, $\mu \mathrm{m}^{2}$} \\
\hline LD & $491 \pm 51$ & $1039 \pm 46$ & $<0.001$ \\
\hline ST & $718 \pm 268$ & $2610 \pm 239$ & 0.001 \\
\hline PM & $530 \pm 61$ & $1276 \pm 55$ & $<0.001$ \\
\hline $\mathrm{RH}$ & $679 \pm 220$ & $2010 \pm 197$ & 0.003 \\
\hline \multicolumn{4}{|c|}{ FCSA FTO, $\mu \mathrm{m}^{2}$} \\
\hline LD & $536 \pm 103$ & $1396 \pm 92$ & $<0.001$ \\
\hline ST & $663 \pm 228$ & $2625 \pm 204$ & $<0.001$ \\
\hline PM & $480 \pm 82$ & $1288 \pm 73$ & $<0.001$ \\
\hline $\mathrm{RH}$ & $566 \pm 38$ & $1980 \pm 213$ & 0.003 \\
\hline \multicolumn{4}{|c|}{ FCSA FTG, $\mu \mathrm{m}^{2}$} \\
\hline LD & $753 \pm 123$ & $2160 \pm 110$ & $<0.001$ \\
\hline ST & $861 \pm 172$ & $2550 \pm 154$ & $<0.001$ \\
\hline PM & $658 \pm 202$ & $1838 \pm 181$ & 0.003 \\
\hline $\mathrm{RH}$ & $623 \pm 208$ & $2100 \pm 186$ & 0.001 \\
\hline \multicolumn{4}{|c|}{ Fibres $/ \mathrm{mm}^{2}$} \\
\hline LD & $1640 \pm 44$ & $553 \pm 39$ & $<0.001$ \\
\hline ST & $1330 \pm 57$ & $400 \pm 51$ & $<0.001$ \\
\hline PM & $1894 \pm 94$ & $687 \pm 84$ & $<0.001$ \\
\hline $\mathrm{RH}$ & $1570 \pm 73$ & $525 \pm 65$ & $<0.001$ \\
\hline \multicolumn{4}{|c|}{ No. of capillaries/fibre } \\
\hline LD & $0.19 \pm 0.02$ & $0.13 \pm 0.02$ & 0.087 \\
\hline ST & $0.53 \pm 0.09$ & $0.41 \pm 0.08$ & 0.337 \\
\hline PM & $0.32 \pm 0.05$ & $0.37 \pm 0.04$ & 0.566 \\
\hline $\mathrm{RH}$ & $0.39 \pm 0.08$ & $0.39 \pm 0.07$ & 0.981 \\
\hline \multicolumn{4}{|c|}{ STO fibre area/capillary, $\mu \mathrm{m}^{2}$} \\
\hline LD & $2883 \pm 722$ & $5092 \pm 645$ & 0.057 \\
\hline ST & $1068 \pm 947$ & $4729 \pm 847$ & 0.024 \\
\hline PM & $1479 \pm 282$ & $2228 \pm 252$ & 0.088 \\
\hline $\mathrm{RH}$ & $1579 \pm 1223$ & $5432 \pm 1094$ & 0.051 \\
\hline \multicolumn{4}{|c|}{ FTO fibre area/capillary, $\mu \mathrm{m}^{2}$} \\
\hline LD & $2358 \pm 1060$ & $9186 \pm 948$ & 0.002 \\
\hline ST & $1256 \pm 1117$ & $6962 \pm 999$ & 0.007 \\
\hline PM & $2022 \pm 509$ & $3360 \pm 455$ & 0.091 \\
\hline $\mathrm{RH}$ & $1823 \pm 999$ & $7078 \pm 893$ & 0.006 \\
\hline \multicolumn{4}{|c|}{ FTG fibre area/capillary, $\mu \mathrm{m}^{2}$} \\
\hline LD & $7892 \pm 2632$ & $23320 \pm 2354$ & 0.003 \\
\hline ST & $3370 \pm 2003$ & $15303 \pm 1792$ & 0.003 \\
\hline PM & $2538 \pm 2310$ & $11084 \pm 2066$ & 0.028 \\
\hline $\mathrm{RH}$ & $2864 \pm 1775$ & $8516 \pm 1587$ & 0.049 \\
\hline \multicolumn{4}{|c|}{ Mean fibre area/capillary, $\mu \mathrm{m}^{2}$} \\
\hline LD & $3513 \pm 900$ & $14560 \pm 805$ & 0.001 \\
\hline ST & $1665 \pm 1346$ & $9281 \pm 1204$ & 0.004 \\
\hline PM & $1915 \pm 701$ & $4430 \pm 627$ & 0.032 \\
\hline $\mathrm{RH}$ & $1685 \pm 1169$ & $6150 \pm 1046$ & 0.025 \\
\hline
\end{tabular}


Table 3

Biochemical characteristics of $L D, S T, P M$ and $R H$ in wild boar and domestic pig (LSM $\pm S E)$

\begin{tabular}{|c|c|c|c|}
\hline & Wild boar & Domestic pig & $P$ \\
\hline \multicolumn{4}{|c|}{ Total DNA, mg } \\
\hline ST & $51.11 \pm 15.75$ & $248.1 \pm 14.08$ & $<0.001$ \\
\hline PM & $86.06 \pm 18.76$ & $224.6 \pm 16.78$ & $<0.001$ \\
\hline $\mathrm{RH}$ & $34.58 \pm 5.55$ & $69.86 \pm 4.97$ & 0.002 \\
\hline \multicolumn{4}{|c|}{ Total RNA, mg } \\
\hline ST & $29.37 \pm 12.17$ & $138.5 \pm 10.9$ & $<0.001$ \\
\hline PM & $41.66 \pm 8.74$ & $107.2 \pm 7.8$ & $<0.001$ \\
\hline $\mathrm{RH}$ & $17.96 \pm 2.07$ & $36.15 \pm 1.85$ & $<0.001$ \\
\hline \multicolumn{4}{|c|}{ Total protein, $\mathrm{g}$} \\
\hline ST & $6.72 \pm 2.83$ & $35.22 \pm 2.54$ & $<0.001$ \\
\hline PM & $10.81 \pm 3.29$ & $34.83 \pm 2.94$ & $<0.001$ \\
\hline $\mathrm{RH}$ & $4.07 \pm 0.79$ & $9.22 \pm 0.71$ & 0.002 \\
\hline \multicolumn{4}{|c|}{$D N A, \mu g / g$} \\
\hline LD & $1286 \pm 29$ & $1083 \pm 26$ & 0.001 \\
\hline ST & $1502 \pm 34$ & $1199 \pm 30$ & $<0.001$ \\
\hline PM & $1565 \pm 54$ & $1190 \pm 48$ & 0.001 \\
\hline $\mathrm{RH}$ & $1525 \pm 67$ & $1270 \pm 60$ & 0.025 \\
\hline \multicolumn{4}{|c|}{$\mathrm{RNA}, \mu \mathrm{g} / \mathrm{g}$} \\
\hline LD & $650 \pm 59$ & $540 \pm 53$ & 0.206 \\
\hline ST & $864 \pm 56$ & $670 \pm 50$ & 0.038 \\
\hline PM & $758 \pm 29$ & $568 \pm 26$ & 0.002 \\
\hline $\mathrm{RH}$ & $794 \pm 58$ & $672 \pm 52$ & 0.160 \\
\hline \multicolumn{4}{|c|}{ Protein, mg/g } \\
\hline LD & $198.9 \pm 5.2$ & $187.6 \pm 4.7$ & 0.152 \\
\hline ST & $197.0 \pm 5.0$ & $169.2 \pm 4.5$ & 0.004 \\
\hline PM & $195.9 \pm 7.9$ & $184.2 \pm 7.0$ & 0.301 \\
\hline $\mathrm{RH}$ & $180.4 \pm 2.8$ & $165.5 \pm 2.5$ & 0.006 \\
\hline \multicolumn{4}{|c|}{$\mathrm{CK}, \mathrm{IU} / \mathrm{mg}$ protein } \\
\hline LD & $22.24 \pm 1.06$ & $24.14 \pm 0.95$ & 0.223 \\
\hline ST & $20.85 \pm 0.83$ & $25.58 \pm 0.75$ & 0.004 \\
\hline PM & $19.91 \pm 1.16$ & $23.67 \pm 1.04$ & 0.047 \\
\hline $\mathrm{RH}$ & $17.92 \pm 0.71$ & $22.21 \pm 0.63$ & 0.003 \\
\hline \multicolumn{4}{|c|}{ LDH, IU/mg protein } \\
\hline LD & $3.09 \pm 0.17$ & $3.41 \pm 0.15$ & 0.211 \\
\hline ST & $2.31 \pm 0.09$ & $2.69 \pm 0.08$ & 0.016 \\
\hline PM & $2.17 \pm 0.16$ & $2.78 \pm 0.14$ & 0.026 \\
\hline $\mathrm{RH}$ & $1.28 \pm 0.24$ & $1.92 \pm 0.22$ & 0.086 \\
\hline \multicolumn{4}{|c|}{ ICDH, IU/g protein } \\
\hline LD & $25.64 \pm 1.82$ & $6.83 \pm 1.62$ & $<0.001$ \\
\hline ST & $35.50 \pm 1.53$ & $15.11 \pm 1.37$ & $<0.001$ \\
\hline PM & $45.07 \pm 3.19$ & $17.84 \pm 2.85$ & $<0.001$ \\
\hline $\mathrm{RH}$ & $54.78 \pm 4.82$ & $29.27 \pm 4.31$ & 0.006 \\
\hline \multicolumn{4}{|c|}{ LDH: ICDH } \\
\hline LD & $123 \pm 53$ & $526 \pm 47$ & $<0.001$ \\
\hline ST & $66.0 \pm 13.2$ & $180.6 \pm 11.8$ & $<0.001$ \\
\hline PM & $50.7 \pm 11.8$ & $159.6 \pm 10.6$ & $<0.001$ \\
\hline $\mathrm{RH}$ & $24.5 \pm 17.6$ & $75.7 \pm 15.8$ & 0.067 \\
\hline
\end{tabular}


In addition, the lower proportion of oxidative fibres in DP may contribute to the lower DNA concentration because it has been shown previously in rat and pig skeletal muscle that slow oxidative fibres exhibited a higher nucleus : fibre area ratio compared with fast glycolytic fibres (Tseng et al. 1994, Quiroz-Rothe \& Rivero 2004). The RNA concentrations were lower in ST $(P=0.038)$ and PM $(P=0.002)$ of $D P$, but no difference between wild and domestic pigs could be observed in $L D$ and RH. Because DNA and RNA concentrations were reduced to a similar extent, RNA : DNA ratio was not different between WB and DP (data not shown). In DP, the DNA : protein ratio was smaller in PM (WB 7.99 \pm 0.28 , DP $6.50 \pm 0.25$; $P=0.006$ ) and tended to be smaller in LD (WB 6.49 \pm 0.27 , DP $5.78 \pm 0.24 ; P=0.087$ ) which can be attributed to the reduced DNA concentration and unchanged protein concentration in these muscles. In contrast, no differences were found in ST and RH which exhibited proportionally reduced DNA and protein concentrations (data not shown). During growth of the muscle (i.e. increasing FCSA), DNA : protein ratio decreases (Hogberg \& Zimmerman 1979, Rehfeldt et al. 2008). Therefore, the lower DNA concentrations and DNA : protein ratios in DP muscles seem to reflect the faster growth of muscle fibres in DP. In addition, no effect of domestication could be observed for RNA : protein ratio (data not shown) with the exception of PM which had a smaller ratio in DP (WB 3.86 \pm 0.19 , DP $3.12 \pm 0.17 ; P=0.02$ ) that resulted from a lower RNA concentration and unchanged protein concentration. Protein concentration of $\mathrm{LD}$ and PM was similar in WB and DP whereas protein concentration was $14 \%$ and $8 \%$ lower in ST $(P=0.004)$ and $\mathrm{RH}(P=0.006)$, respectively, for $D P$. The determination of protein in this study was based on wet tissue and included myofibrillar and sarcoplasmic protein but also proteins from connective tissue. Therefore, the slightly lower protein concentration in DP muscles could be attributed to higher proportions of water or lipid or glycogen. Slow-twitch oxidative fibres contain a greater lipid concentration compared with fast-twitch fibres (Handel \& Stickland 1987, Essén-Gustavsson et al. 1994, Malenfant et al. 2001). On the other hand, intrafascicular adipocytes are the main determinants for intramuscular fat content (Gondret et al. 1998, Gondret \& Lebret 2002). In fact, RH - which displays the greatest proportion of STO fibres among the muscles examined in the present study - seems to exhibit the lowest protein concentration. In contrast, each DP muscle displayed both lower proportions of oxidative fibres and lower protein concentrations. Moreover, no clear relationship between intramuscular fat content and fibre type composition within a muscle has been demonstrated so far (Lefaucheur 2010). On the other hand, Essén-Gustavsson \& Lindholm (1984) reported greater glycogen contents in $M$. gluteus, LD and ST muscles of DP compared with WB which is associated with the higher glycogen content of glycolytic fibres (Swatland 1975). However, it is questionable whether the low amounts of glycogen could account for differences in protein concentration.

Specific CK activity (expressed as IU per mg protein) was about 1.2-fold higher in DP than in WB for ST, PM and RH ( $P \leq 0.047)$. Creatine kinase provides ATP rapidly from the cleavage of phosphocreatine and is the prerequisite for short-time maximum muscle activity. Thus, CK activity was shown to be highest in FTG, lower in FTO and lowest in STO fibres (Yamashita \& Yoshioka 1991). Therefore, the shift in fibre type composition, which was most pronounced for FTG fibres, likely explains the increase in specific CK activity. Although in LD, fibre type composition was changed in a similar way as in the other muscles, specific CK activity was not different between WB and DP $(P=0.223)$. 
Specific LDH activity (a marker for the anaerobic glycolytic energy production) tended to be higher in $\mathrm{RH}$ of DP $(P=0.086)$ and was about 1.2-fold greater in ST and PM of DP $(P \leq 0.026)$. Fast glycolytic fibres show higher LDH activities than STO fibres (Takehura \& Yoshioka 1987) and an increased proportion of FTG fibres is often associated with increased LDH activity in pig muscle (Lefaucher \& Vigneron 1986, Lebret et al. 1999). For LD, no effect of domestication on specific LDH activity could be detected $(P=0.211)$.

In each muscle, the specific ICDH activity (a marker for the oxidative capacity of metabolism) was markedly lower in DP compared with WB ( $-47 \%$ to $-73 \% ; P \leq 0.006)$ which is in agreement with the lower percentage of oxidative fibres (the sum of STO and FTO fibres, data not shown). A positive relationship between the proportion of oxidative fibres and ICDH activity has been shown for pigs (Huber et al. 2007, Lösel et al. 2011). Interestingly, in the present study, the differences between wild and domestic pigs were larger for specific ICDH activity than for specific $L D H$ activity. As a result, the $L D H$ : ICDH ratio was 4-fold higher in LD, 2.7-fold in ST, 3.1-fold in PM (each $P<0.001$ ) but only tended to be 3 -fold in $\mathrm{RH}(P=0.067)$. The fact that LD exhibited no differences for CK and LDH activity between WB and DP although fibre type composition was changed similarly to the other muscles examined, suggests that fibre type composition alone cannot explain the extent of oxidative or glycolytic metabolism in a muscle.

In conclusion, the comparison of growing DP with their wild ancestors of the same age showed the superiority of DP in body and muscle growth. However, relative weights of the interior tenderloin muscle (PM) or the economically non-relevant $\mathrm{RH}$ muscle were lowered in DP, whereas the exterior ham muscle (ST) was disproportionally enlarged probably due to the selection of lean growth. Our data suggest that the greater absolute muscle mass in DP can be attributed to intensified fibre hypertrophy without affecting total fibre number. This was reflected by reduced DNA concentrations and smaller DNA : protein ratios in muscle. Moreover, the capillary density was remarkably reduced in muscles of DP as a result of hypertrophic processes. In consequence, the impaired supply with oxygen and nutrients may be one reason for the shift to the glycolytic muscle metabolism as indicated by a greater proportion of FTG fibres at the expense of FTO fibres, higher specific CK and LDH activity and lower ICDH activity. The extent of the domestication-induced changes differed among muscles with the greatest changes occurring in the exterior ham muscle (ST). However, the LD muscle seems to be of the same economic interest and exhibited comparable changes in myofibre type distribution without domestication-typically changes in muscle enzyme activities.

\section{Acknowledgements}

We thank Dr. Bernd Stabenow and his team and the zoological garden Schwerin (Germany) for taking care of the animals. Dr. Ralf Pfuhl and his team are acknowledged for slaughtering. We are grateful to Dr. Charlotte Rehfeldt for fruitful discussions to this project. Marie JugertLund and Angela Steinborn are acknowledged for excellent technical assistance. 


\section{References}

Bader R (1983) [Histometrical and histological investigations of muscles of domestic pigs and wild boars]. Berl Münch Tierärztl Wochenschr 96, 89-97 [in German]

Bee G (2004) Effect of early gestation feeding, birth weight, and gender of progeny on muscle fiber characteristics of pigs at slaughter. J Anim Sci 82, 826-836

Essén-Gustavsson B, Lindholm A (1984) Fiber types and metabolic characteristics in muscles of wild boars, normal and halothane sensitive swedish landrace pigs. Comp Biochem Physiol A Physiol 78, 67-71

Essén-Gustavsson B, Karlsson A, Lundström K, Enfält AC (1994) Intramuscular fat and muscle fibre lipid contents in halothane-gene-free pigs fed high or low protein diets and its relation to meat quality. Meat Sci 38, 269-277

GfE (Gesellschaft für Ernährungsphysiologie) (2006) [Recommendations of energy and nutrient intake in pigs]. DLG-Verlag, Frankfurt am Main, Germany [in German]

Fiedler I, Rehfeldt C, Albrecht E, Henning M (1998) Histophysiological features of skeletal muscle and adrenal glands in wild-type and domestic pigs during growth. Arch Tierz 41, 489-495

Giuffra E, Kijas JMH, Amarger V, Carlborg Ö, Jeon JT, Andersson L (2000) The Origin of the Domestic Pig: Independent Domestication and Subsequent Introgression. Genetics 154, 1785-1791

Gondret F, Mourot J, Bonneau M (1998) Comparison of intramuscular adipose tissue cellularity in muscles differing in their lipid content and fibre type composition during rabbit growth. Livest Prod Sci, 54, 1-10

Gondret F, Lebret B (2002) Feeding intensity and dietary protein level affect adipocyte cellularity and lipogenic capacity of muscle homogenates in growing pigs, without modification of the expression of sterol regulatory element binding protein. J Anim Sci, 80, 3184-3193

Guth L, Samaha FJ (1970) Procedure for the histochemical demonstration of actomyosin ATPase. Exp Neurol $28,365-367$

Handel SE, Stickland NC (1987) Muscle cellularity and birth weight. Anim Prod 44, 311-317

Hogberg MG, Zimmerman DR (1979) Effects of Protein Nutrition in Young Pigs on Developmental Changes in the Body and Skeletal Muscles during Growth. J Anim Sci, 49, 472-481

Huber K, Petzold J, Rehfeldt C, Ender K, Fiedler I (2007) Muscle energy metabolism: structural and functional features in different types of porcine striated muscles. J Muscle Res Cell Motil 28, 249-258

King JWB, Roberts RC (1960) Carcass length in the bacon pig; its association with vertebrae numbers and prediction from radiographs of the young pig. Anim Prod 2, 59-65

Larson G, Dobney K, Albarella U, Fang M, Matisoo-Smith E, Robins J, Lowden S, Finlayson H, Brand T, Willerslev E, Rowley-Conwy P, Andersson L, Cooper A (2005) Worldwide Phylogeography of Wild Boar Reveals Multiple Centers of Pig Domestication. Science 307, 1618-1621

Larzul C, Lefaucheur L, Ecolan P, Gogué J, Talmant A, Sellier P, Le Roy P, Monin G (1997) Phenotypic and genetic parameters for longissimus muscle fiber characteristics in relation to growth, carcass, and meat quality traits in large white pigs. J Anim Sci 75, 3126-3137

Lebret B, Le Roy P, Monin G, Lefaucheur L, Caritez JC, Talmant A, Elsen JM, Sellier P (1999) Influence of the three RN genotypes on chemical composition, enzyme activities, and myofiber characteristics of porcine skeletal muscle. J Anim Sci 77, 1482-1489

Lefaucheur L, Vigneron P (1986) Post-natal changes in some histochemical and enzymatic characteristics of three pig muscles. Meat Sci 16, 199-216

Lefaucheur L (2010) A second look into fibre typing - Relation to meat quality. Meat Sci 84, 257-270

Lösel D, Nürnberg G, Rehfeldt C (2011) Regional differences in micro-structural and biochemical characteristics of growth and metabolism in semitendinosus muscle of 28-day old piglets. Meat Sci 87, 19-25

Malenfant P, Joanisse DR, Thériault R, Goodpaster BH, Kelley DE, Simoneau JA (2001) Fat content in individual muscle fibers of lean and obese subjects. Int J Obes Relat Metab Disord 25, 1316-1321 
Mignon-Grasteau S, Boissy A, Bouix J, Faure JM, Fisher AD, Hinch GN, Jensen $P$, Le Neindre $P$, Mormède $P$, Prunet $P$, Vandeputte M, Beaumont C (2005) Genetics of adaptation and domestication in livestock. Livest Prod Sci 93, 3-14

Müller E, Moser G, Bartenschlager H, Geldermann H (2000) Trait values of growth, carcass and meat quality in Wild Boar, Meishan and Pietrain pigs as well as their crossbred generations. J Anim Breed Genet 117, 189-202

Müller E, Rutten M, Moser G, Reiner G, Bartenschlager H, Geldermann H (2002) Fibre structure and metabolites in M. longissimus dorsi of Wild Boar, Pietrain and Meishan pigs as well as their crossbred generations. J Anim Breed Genet 119, 125-137

Novikoff AB, Shin WY, Drucker J (1961) Mitochondrial localization of oxidative enzymes: staining results with two tetrazolium salts. J Biophys Biochem Cytol 9, 47-61

Oksbjerg N, Petersen JS, Sørensen IL, Henckel P, Vestergaard M, Ertbjerg P, Møller AJ, Bejerholm C, Støier S (2000) Long-term changes in performance and meat quality of Danish Landrace pigs: a study on a current compared with an unimproved genotype. Anim Sci 71, 81-92

Peterson GL (1977) A simplification of protein assay method of Lowry et al. which is more generally applicable. Anal Biochem 83, 346-356

Quiroz-Rothe E, Rivero JL (2004) Coordinated expression of myosin heavy chains, metabolic enzymes, and morphological features of porcine skeletal muscle fiber types. Microsc Res Tech 65, 43-61

Rehfeldt C, Walther K (1997) A combined assay for DNA, protein and incorporated [3H] label in cultured muscle cells . Anal Biochem 251, 294-297

Rehfeldt C, Henning M, Fiedler I (2008) Consequences of pig domestication for skeletal muscle growth and cellularity. Livest Sci 116, 30-41

Rehfeldt C, Stabenow B, Pfuhl R, Block J, Nürnberg G, Otten W, Metges CC, Kalbe C (2012) Effects of limited and excess protein intakes of pregnant gilts on carcass quality and cellular properties of skeletal muscle and subcutaneous adipose tissue in fattening pigs. J Anim Sci 90, 184-196

Ruusunen M, Puolanne E (2004) Histochemical properties of fibre types in muscles of wild and domestic pigs and the effect of growth rate on muscle fibre properties. Meat Sci 67, 533-539

Schurmann M (1984) [Comparison of organ weights in wild boar and domestic swine]. PhD Thesis, Tierärztliche Hochschule Hannover, Germany [in German]

Swatland HJ (1975) Relationships between mitochondrial content and glycogen distribution in porcine muscle fibres. Histochem J 7, 459-469

Takehura H, Yoshioka T (1987) Determination of metabolic profiles on single muscle fibres of different types. J Muscle Res Cell Motil 8, 342-348

Tseng BS, Kasper CE, Edgerton VR (1994) Cytoplasm-to-myonucleus ratios and succinate dehydrogenase activities in adult rat slow and fast muscle fibers. Cell Tissue Res 275, 39-49

Wegner W (1971) [Important hereditary characteristic in swine]. Arch Kreislaufforschung 64, 1-22 [in German]

Weiler U, Appell HJ, Kremser M, Hofäcker S, Claus R (1995) Consequences of Selection on Muscle Composition. A Comparative Study on Gracilis Muscle in Wild and Domestic Pigs. Anat Histol Embryol 24, 77-80

Weiler U, Claus R, Schnoebelen-Combes S, Louveau I (1998) Influence of age and genotype on endocrine parameters and growth performance: a comparative study in Wild boars, Meishan and Large White boars. Livest Prod Sci 54, 21-31

Wolkers J, Wensing T, Schonewille JT, van't Klooster AT (1994) Undernutrition in relation to changed tissue composition in wild boar (Sus scrofa). Comp Biochem Physiol A Physiol 108, 623-628

Yamashita K, Yoshioka T (1991) Profiles of creatine kinase isoenzyme compositions in single muscle fibres of different types. J Muscle Res Cell Motil 12, 37-44 